\title{
Time Effect Research of Static Pressure Pile Based on Low Strain Dynamic Test
}

\author{
Jiatao Wang ${ }^{1, a}$, Wei Zhang ${ }^{1, b}$ \\ ${ }^{1}$ Department of Civil Engineering, Shandong Water Polytechnic, Rizhao, China \\ awy_wjt@126.com, bqsct@163.com
}

Keywords: time effect; low strain dynamic test; static pressure pile pile; bearing capacity

Abstract: Through the low strain dynamic test in engineerings, we found that the wave velocity is raised with time. Reasons for the phenomenon are analysed with the theory of stress wave propagation. We found that the increasing of the velocity of the test pile is mainly effected by the of lateral soil, because a soil layer close to the surface of the pile will gradually be formed in a period after piles sunk. When the pile shifted, the soil layer will move together, just like enlarging the section size of the pile. This increases the bearing capacity of the pile. So it can be considered that the enlarging of the velocity is consistent with the increasing of the pile bearing capacity. The study of the velocity increace is benificial for the investigation of the time effect of the static pressure pile bearing capacity.

\section{Introduction}

With the advantages of simple, fast, wide range detection, economical and practical, low strain dynamic test is widely used to detect the structural integrity of the pile as an adjunct to pile engineering quality testing ${ }^{[1]}$. During the testing process in engineerings, we found that wave velocity of the pile will increase with time. And the increasing of the wave velocity is consistent to the bearing capacity, so we can study the time effect of static pile bearing capacity by investigating wave velocity.

\section{Low Strain Dynamic Testing Theory}

In low strain dynamic test, the velocity is an important parameter used to calculate the location of the defect, and the length of the pile. In low strain dynamic test, load is added to the pile top, which generates compressed stress wave in the concrete piles. We can measure the time of the compression wave propagation in concrete to get the longitudinal wave velocity of concrete ${ }^{[2]}$.

When the stress wave propagation in an infinite elastic body, to meet the three-dimensional wave equation, namely

$$
\rho \frac{\partial^{2} \varepsilon}{\partial t^{2}}=c^{2}\left(\frac{\partial^{2} \varepsilon}{\partial x^{2}}+\frac{\partial^{2} \varepsilon}{\partial y^{2}}+\frac{\partial^{2} \varepsilon}{\partial z^{2}}\right)
$$

Where, $\varepsilon$ is the volumetric strain, $c$ is the velocity:

$$
\begin{gathered}
\varepsilon=\frac{\partial u_{x}}{\partial x}+\frac{\partial u_{y}}{\partial y}+\frac{\partial u_{z}}{\partial z} \\
c=\sqrt{\frac{E(1-\mu)}{\rho(1+\mu)(1-2 \mu)}}
\end{gathered}
$$


Where, $\mathrm{E}$ is the elastic modulus and the medium velocity, $\rho$ is mass density, and $\mu$ Poisson ratio. In the slender rod (lateral dimensions much smaller than the wavelength), and the three-dimensional wave equation simplifies to become one dimensional wave equation:

$$
\begin{aligned}
& \frac{\partial^{2} u}{\partial t^{2}}=c^{2} \frac{\partial^{2} u}{\partial x^{2}} \\
& c=\sqrt{E / \rho}
\end{aligned}
$$

After the construction of the pile in the soil, as consolidation occurs, some of the dynamic measurement indicators reflect pile bearing capacity will increase, such as dynamic stiffness and wave velocity.

\section{Field-tests}

Engineering and Site Conditions. Test site soil conditions is showed in Table 1. Test site groundwater levels is about $1.6 \mathrm{~m}$.

Table 1 Geological data of the tested field

\begin{tabular}{l|l|l}
\hline Layer number & Layer name & Depth range[m] \\
\hline 1 & Miscellaneous fill & $0 \sim 1.7$ \\
\hline 2 & Silty clay & $1.7 \sim 2.9$ \\
\hline 3 & Fine sand & $2.9 \sim 7.0$ \\
\hline 4 & Mudstone & $7.0 \sim$ \\
\hline
\end{tabular}

Testing Process. Two methods of low strain dynamic test using are used, one is the reflected wave method and the other transient mechanical impedance method. A hardwood hammer is used in the eflected wave method and a composite stick is used in the mechanical impedance method. Tests are carried out at certain time intervals on the reinforced concrete piles, and identical to the other test conditions. Tests records are shown in Table 2.

Table 2 Changing of site dynamic measurement records over time

\begin{tabular}{c|c|c|c|c|c|c|c|c}
\hline Pile & Pile-sectional & Pile & \multicolumn{3}{|c|}{ Dynamic stiffness $[\mathrm{kN} / \mathrm{mm}]$} & \multicolumn{3}{|c}{ Wave velocity $[\mathrm{m} / \mathrm{s}]$} \\
\cline { 5 - 9 } number & $\begin{array}{c}\text { dimensions } \\
{[\mathrm{mm}]}\end{array}$ & $\begin{array}{c}\text { length } \\
{[\mathrm{m}]}\end{array}$ & $\begin{array}{c}5 \\
\text { days }\end{array}$ & $\begin{array}{c}17 \\
\text { days }\end{array}$ & $\begin{array}{c}\text { Rate of } \\
\text { increase }\end{array}$ & $\begin{array}{c}5 \\
\text { days }\end{array}$ & $\begin{array}{c}17 \\
\text { days }\end{array}$ & $\begin{array}{c}\text { Rate of } \\
\text { increase }\end{array}$ \\
\hline 1 & $300 \times 300$ & 6.5 & 165 & 167 & $1.2 \%$ & 3681 & 3755 & $2.0 \%$ \\
\hline 2 & $300 \times 300$ & 6.5 & 119 & 124 & $4.2 \%$ & 3610 & 3755 & $4.0 \%$ \\
\hline 3 & $300 \times 300$ & 6.5 & 162 & 16.7 & $33.9 \%$ & 3855 & 4177 & $8.3 \%$ \\
\hline
\end{tabular}

From table 2 we can find that both the dynamic stiffness and pile wave velocity all increase in certain degrees with time after the sinking of the pile. The indicators of piles are some different, mainly because of the thickness of each soil are quite different.

Figure 1 shows the comparison of wave velocity of $3 \#$ pile between in 5days and in 17days. 


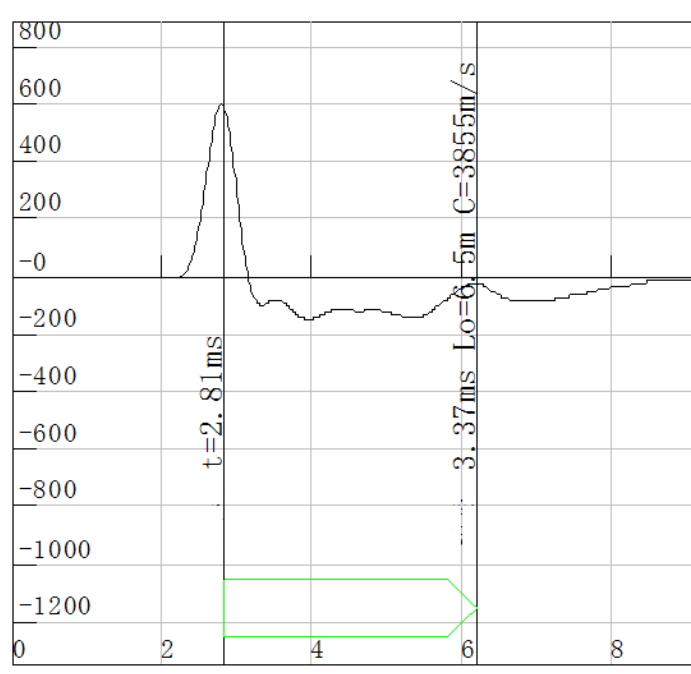

(a) $5 \mathrm{~d}$

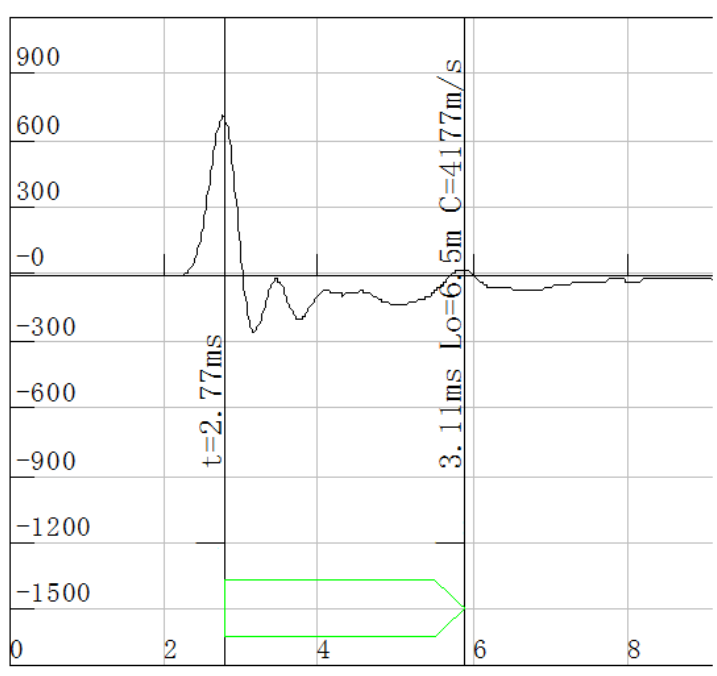

(b) $17 \mathrm{~d}$

Fig. 1 the comparison of wave velocity of $3 \#$ pile between in 5 days and in 17 days

\section{Analysis of Pile Testing Results}

Influence Factors of the Wave Velocity. It can be seen from the above project example that the wave velocity of piles will improve significantly with the growth of the interval. Ignore the changes of the internal factors, such as concrete materials and the water content, and so on, the main reason for this phenomenon include the following aspects:

(1) Soil thixotropic recovery. The soil around the pile disturbance in the pile driving process and the intensity of is significantly reduced. But as time goes on, the strength of cohesive soil is gradually recovery because of the thixotropic effect ${ }^{[3]}$.

(2) Consolidation ${ }^{[4]}$. During the static pressure pile driving process, due to the soil squeezing effect, soil around the pile is disturbed, and then the pore water pressure will have a substantial rise. The increase of pore water pressure will lead to the reduction of soil strength. But after construction, the excess pore water pressure in the foundation soil will dissipate and the soil around the pile will consolidate. Then the soil strength is restored and the pile bearing capacity will be increased.

(3) Soil-shell effect. Affected by the function of vertical shear and lateral compression during the pile driving process, soils around the pile become completely plastic zone. After a period of standing and consolidation time, a crust layer close to the pile surface will gradually be formed. When the pile displacement occurs, the crust layer will move together with the pile, which is essentially to make the pile lateral surface friction area increases, and then the wave velocity of the pile increase.

Overall, the change of the pile "horizontal dimension" ${ }^{[5]}$ is a main factor of the improvement of the wave velocity. That's to say the increment of the wave velocity mainly caused by the increasing of the transverse dimension. We can see the maximum growth rate of wave velocity is about of $8.3 \%$ in table 2. Taking into account the the values of the comparison wave velocity is not measured by pile sinking end time, five days later, so the wave velocity will be greater from the beginning.

Relationship between the Improvement of Pile Wave Velocity and Bearing Capacity. The dynamic stiffness measured by low strain dynamic test can well reflect the growth of the bearing capacity of the pile. While the improvement of wave velocity is associated with the improvement of the dynamic stiffness. So we can say that the improvements of between the wave velocity and bearing capacity are closely related. After obtaining sufficient comparative information, we 
can get the bearing capacity of the pile by studying the variation of wave velocity. It is a very simple way, and works very meaningful.

\section{Summary}

We found that the wave velocity increases with the time after the pile piling. Reaserch indicates that the main reason for this phenomenon is caused by the increasing of the transverse dimension, which is called soil-shell effect.

The growth of the pile wave velocity is affected by many factors, but mainly caused by the contribution of soils near pile shaft. After the construction of the prestressed pipe piles, soils of pile shaft will experience a complex process of thixotropic recovery and consolidation. The change of soils near pile shaft has led to the improvement of the wave velocity. In this process, the enlarging of the wave velocity is consistent with the increasing of the pile bearing capacity. In some way, we can get the pile bearing capacity by the testing of the wave velocity at different stages.

\section{References}

[1] CHEN Jian-gong, HU Jun-qiang, ZHANG Yong-xing. Identification of surrounding rock quality based on dynamic testing technology of integrated anchor[J]. Rock and Soil Mechanics, 2009, 30(6): 1799-1804.

[2] Li Qi, et al. Propagation of stress waves in a plate-pile system: ex-perimental studies. Rock and Soil Mechanics, 2002, 23(4): 459-464.

[3] WANG Jia-tao, ZHOU Jian, ZHANG Ming-yi [J]. Computation of bearing capacity of jacked piles based on spherical cavity expansion theory and time effect. Chinese Journal of Underground Space and Engineering, 2010, 6(5): 964-968.

[4] $\mathrm{Wu} \mathrm{WB}$, Wang $\mathrm{KH}$, et al. Soil-pile interaction in the pile vertical vibration considering true three-dimensional wave effect of soil. International Journal for Numerical and Analytical Methods in Geomechanics, 2013, 37: 2860-2876.

[5] ZHANG Ming-yi, SHI Wei, WANG Chong-ge. Time effect on the ultimate bearing capacity of static pressed pile[J]. Chinese Journal of Rock Mechanics and Engineering, 2002, 21: 2601-2604. 